\title{
INTUBATION AND OTHER EXPERIENCES IN CARDIAC SURGERY: THE CONSUMER'S VIEWS
}

\author{
B. Paiement, M. Boulanger, C.W. Jones, And M. Roy
}

WHILE A FEW GROUPS reserve postoperative mechanical ventilation after cardiac surgery for selected cases, ${ }^{1.2}$ the majority of centers have adopted a policy of routine respiratory assistance ${ }^{3-5}$ either during the first night or for a few hours after operation. Recently, there has been a tendency to wean patients and extubate the trachea earlier. ${ }^{6.7}$ It has been shown that this can be accomplished with safet $y^{8,9}$ in a large proportion of cases.

Advocates of early extubation stress greater comfort of the patients, lower requirements for sedation, earlier mobilization, fewer respiratory complications, and shorter stay in the intensive care unit (I.C.U.) and in hospital.

In our institution, we have been using a conservative approach of routine overnight ventilation. Before reconsidering our policy, it was decided to assess the relative comfort or discomfort caused by tracheal intubation.

\section{Material and Methods}

One hundred consecutive adult patients undergoing open-heart operations were studied. The group included 30 women aged 22 to 69 years (mean: 52.9 years) and 70 men, aged 21 to 71 years (mean: 52.3 years). Table I lists the operations.

\section{Preoperative visit}

All patients were seen on the eve of operation, were advised that they would awaken with a

B. Paiement, M.D., F.R.C.P.(C), Associate Professor and M. Boulanger, M.D., F.R.C.P.(C), Associate Professor, University of Montreal; Attending Anesthesiologists, Montreal Heart Institute, Montreal, Quebec, Canada.

C.W. Jones, M.D., F.R.C.S.(C), Department of Surgery, Montreal Heart Institute, Montreal, Quebec, Canada.

M. Roy, R.R.T., Montreal Heart Institute, Montreal, Quebec, Canada.

This work was presented in part at the Fall Meeting of the Association of Cardiac Anesthesiologists, Chicago, III. October 1978.

Address for reprints: $\mathrm{Dr}$, B. Paiement, Département d'Anesthésie-Réanimation, Montreal Heart Institute, 5000 East Belanger Street, Montreal, Quebec, H1T 1C8, Canada.

Canad. Anaesth. Soc. J., vol. 26, no. 3, May 1979
TABLE I

\begin{tabular}{lr}
\hline \multicolumn{1}{c}{ Surgical Procedures } & Cases \\
\hline Aorto-coronary bypass graft & 66 \\
Resection of ventricular aneurism + ACBG & 4 \\
ACBG + aortic valve replacement & 1 \\
ACBG + mitral valve replacement & 1 \\
Aortic valve replacement & 8 \\
Mitral valve replacement & 4 \\
Mitral valve replacement & \\
+ tricuspid valvuloplasty & 3 \\
Mitral and aortic valve replacement & 3 \\
Mitral commissurotomy & 6 \\
Pulmonary valvulotomy & 1 \\
ASD closure & 3 \\
\end{tabular}

tracheal tube in place and were given general reassurance.

\section{Premedication}

Hydroxyzine $50 \mathrm{mg}$ (per os) was prescribed one and a half hours before induction and pentobarbitone 1.0 to $2.0 \mathrm{mg} \cdot \mathrm{kg}^{-1}$ with scopolamine $0.4 \mathrm{mg}$ was given intramuscularly one hour before induction.

\section{Sedation score}

On arrival in the operating room the sedation was assessed according to a scoring system which has been in use for many years in our institution. If the premedication appears too weak a zero (no apparent effect) or negative score is given (minus one $(-1)$ if the patient seems anxious and minus two $(-2)$ if he is markedly anxious, crying or agitated). A positive score is given if the premedication appears effective: $(+1)$ if the patient appears calm, $(+2)$ if he is drowsy, $(+3)$ for a patient who is asleep but awakes when stimulated. If a patient does not awake when stimulated he is assessed a (+4) score. A score of $(+5)$ refers to gross respiratory or circulatory depression. Table II summarizes our sedation score.

\section{Anaesthesia}

The choice of anaesthetic was left to the attending anaesthetist. Two regimens were used: (a) Intravenous induction (morphine up to $30 \mathrm{mg}$, 


\section{TABLE II}

\begin{tabular}{l}
\hline Assessment of the preoperative sedation \\
\hline Score \\
$5=$ Gross respiratory or cardiovascular depression \\
$4=$ Asleep does not wake when stimulated \\
$3=$ Asleep but wakes when stimulated \\
$2=$ Drowsy \\
$1=$ Calm \\
$0=$ No apparent effect \\
$-1=$ Anxious \\
$-2=$ Anxious and agitated (crying, etc.) \\
\hline
\end{tabular}

diazepam $0.2-0.3 \mathrm{mg}-\mathrm{kg}^{-1}$ and succinylcholine); maintenance; nitrous oxide-oxygen with intravenous morphine administered to a total dose of $1.5 \mathrm{mg} \cdot \mathrm{kg}^{-1}$.

(b) Intravenous and inhalation induction (morphine $5-10 \mathrm{mg}$, diazepam $0.3 \mathrm{mg} \cdot \mathrm{kg}^{-1}$, thiopentone 50-75 mg, succinylcholine; controlled respiration with nitrous oxide, oxygen, halothane, for one or two minutes, then tracheal intubation); maintenance with nitrous oxide-oxygen-halothane with small increments of morphine intravenously (total dose 20 to $40 \mathrm{mg}$ ) as analgesic supplement.

Intravenous nitroglycerin, droperidol or deepening of halothane anaesthesia were used to prevent or treat hypertensive episodes.

\section{Postoperutive ventilatory assistance}

In the intensive care unit the patients were ventilated using volumetric respirators with tidal volumes of 10 to $12 \mathrm{ml} \cdot \mathrm{kg}^{-1}, 10$ times per minute. Mechanical dead spaces were used to control $\mathrm{Pa}_{\mathrm{a}_{\left(\mathrm{O}_{2}\right.}}$ between 4.26 and $5.32 \mathrm{kPa}$ ( 32 and 40 torr).

\section{Sedation}

Morphine, 2 to $5 \mathrm{mg}$ or diazepam, 2.5 to $5 \mathrm{mg}$, were administered intravenously as needed to keep the patients comfortable or as the first measure in the event of postoperative hypertensive episodes.

\section{Length of Ventilatory Support}

Patients who had short surgical procedures such as closure of ASD and mitral commisurotomy had the tracheal tube removed if they were alert and stable a few hours after operation. Otherwise, the weaning was started the next morning.

\section{Interview}

All patients were questioned on the fifth or sixth postoperative day. Questions relating to their general feeling about both anaesthesia and operation were asked first, to provide them with the opportunity to volunteer information about the tracheal tube. Table III describes the questionnaire.

\section{Results}

\section{Preoperative anxiery (patients' view)}

Thirty of the 100 patients felt very apprehensive before the operation, thirty-nine rated themselves as "normal" and the other 31 felt absolutely confident.

\section{Postoperative assessment}

Fifty-three of the patients felt that the operation had been an easier experience than they had expected; 36 found the experience consistent with expectations, with 12 finding it easy while 24 found it difficult. Ten patients thought it was worse than they had forecast. Table IV relates the patients' view of their preoperative anxiety and their general appraisal of the experience.

\section{Preoperative sedation}

The anaesthetist gave a zero score (no apparent effect) to five patients and described three more as anxious $(-1)$. The sedation was otherwise found satisfactory. Thirty-four patients were judged calm $(+1), 37$ were drowsy $(+2), 17$ were sleeping when not stimulated $(+3)$ and 4 did not respond to stimulation $(+4)$. No patient had gross respiratory or circulatory depression $(+5)$.

When asked to assess their own preoperative sedation, 52 patients stated that they did not remember anything of the operating room, 11 of the remaining 48 thought their sedation was more effective than the score given by the anaesthetist. 30 gave an assessment similar to that of the anaesthetist and 7 gave a lower one. Three patients remembered being anxious in the operating room before induction of anaesthesia. Table $V$ shows the assessment of the preoperative sedation by the anaesthetist and by the patient.

\section{Awakening after operation}

The nurses' notes showed that 22 patients were awake or rousable within one hour of arrival in the I.C.U. This number rose to 39 two hours after arrival, to 58 after three hours, to 69 at four hours, to 82 at five hours and to 91 at six hours.

When questioned on the fifth postoperative day, only eight of the patients remembered being conscious "sometime in the afternoon" of the day of operation, although two thirds of them had 
TABLE III

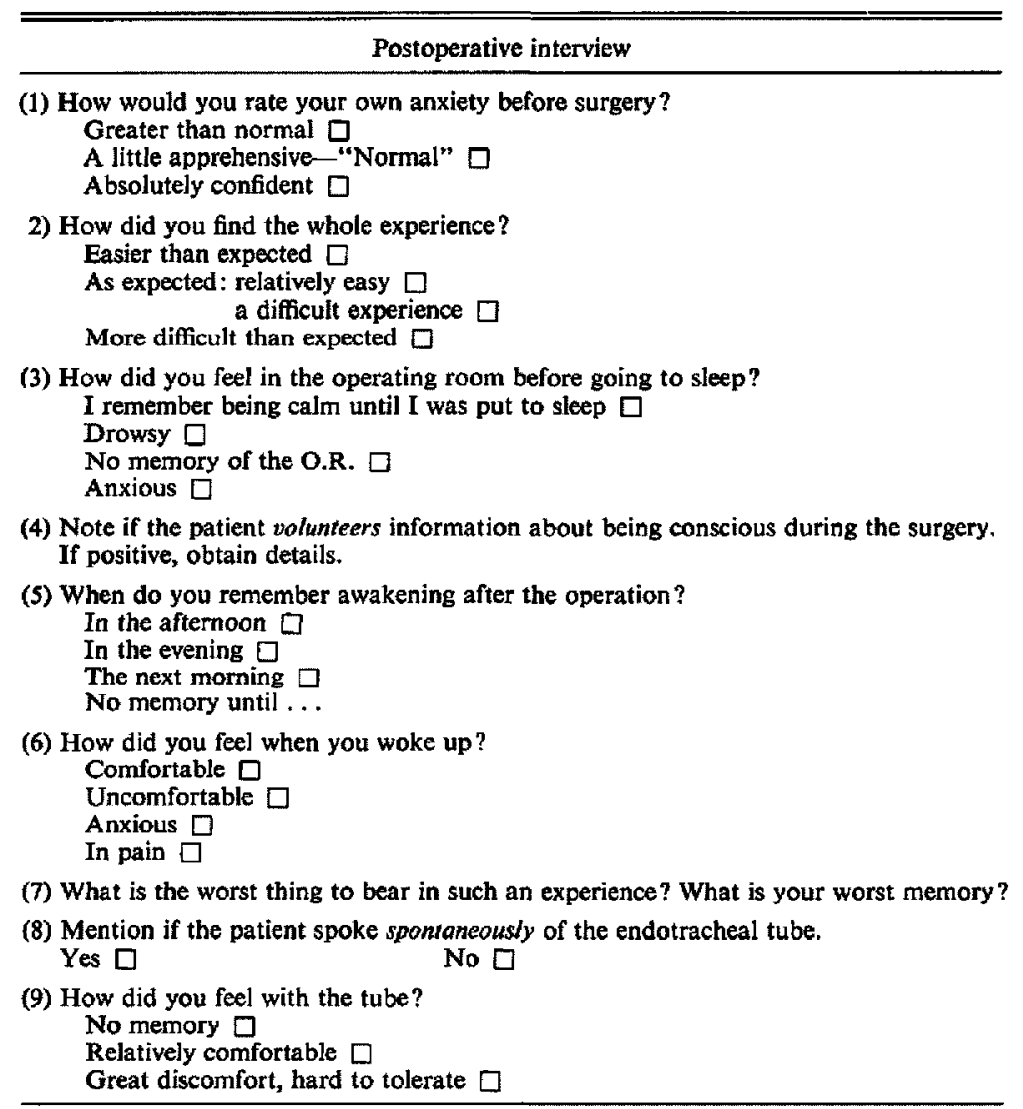

been admitted to the I.C.U. between 1200 and 1400 hours. Twenty-eight remembered waking sometime in the evening and 23 either during the night or in the early hours of morning. Forty-two patients had no memory of anything until after tracheal extubation.

\section{Comfort}

Forty patients were described in the nurses' notes as uncomfortable, restless or anxious sometime during the ventilatory support period. When interviewed, only five of these 40 patients remembered being distressed or uncomfortable. The remainder did not remember (19 cases) or said they remembered being comfortable (16 cases) (Table I). Only eight of the 100 patients remembered being uncomfortable.

\section{Sedation}

While tracheal tubes were in place in the
I.C.U., the average total dose of morphine was $10.7 \mathrm{mg}$ (range $01040 \mathrm{mg}$ ) per patient and that of diazepam was $6.6 \mathrm{mg}$ (range 0 to $45 \mathrm{mg}$ ) per patient. Three of the 100 patients required doses greater than $30 \mathrm{mg}$ of morphine and/or diazepam. The 53 patients who had received the smaller doses of morphine as an analgesic supplement to halothane anaesthesia had sedative requirements little different from the 43 who had received 1.0 to $1.5 \mathrm{mg} \cdot \mathrm{kg}^{-1}$ of morphine. The morphine requirement per patient in the first group was $11.2 \mathrm{mg}$ compared to $10.3 \mathrm{mg}$ for the second group. The diazepam requirement per patient in the first group was $6.9 \mathrm{mg}$ compared to $6.3 \mathrm{mg}$ in the second group.

\section{Duration of tracheal intubation}

Seven of the patients who were awake and stable were extubated early (three to six hours after operation). Seventy-five patients were 
TABLE IV

\begin{tabular}{ccclr}
\hline \multicolumn{2}{c}{ Before operation the patient felt } & & \multicolumn{2}{c}{ He found the experience } \\
$\begin{array}{c}\text { Very } \\
\begin{array}{c}\text { apprehensive } \\
14\end{array}\end{array}$ & $\begin{array}{c}\text { A little } \\
\text { apprehensive "normal" }\end{array}$ & $\begin{array}{c}\text { Absolutely } \\
\text { confident } \\
20\end{array}$ & $\begin{array}{l}\text { Easier } \\
\text { than } \\
\text { expected: }\end{array}$ & 53 \\
1 & 6 & 5 & $\begin{array}{l}\text { As expected } \\
\text { Relatively easy } \\
\text { A difficult experience }\end{array}$ & 12 \\
& 13 & 3 & $\begin{array}{l}\text { More difficult than } \\
\text { expected }\end{array}$ & 10 \\
7 & 0 & 3 & No opinion & 1 \\
30 & 39 & 1 & & 100 \\
\hline
\end{tabular}

TABLE $V$

Premedication-Assessment OF THE SEDATION

\begin{tabular}{|c|c|c|c|c|c|}
\hline \multirow{2}{*}{\multicolumn{2}{|c|}{ By the anaesthetist }} & \multicolumn{4}{|c|}{ By the patient } \\
\hline & & \multicolumn{3}{|c|}{ He felt } & \multirow{2}{*}{$\begin{array}{l}\text { Has no memory } \\
\text { of the O.R. }\end{array}$} \\
\hline Score & Casses & Anxious & Quiet & Drowsy & \\
\hline 5 Resp. or C.V. depression & 0 & & & & \\
\hline $\begin{array}{l}4 \text { Asleep does not wake when } \\
\text { stimulated. }\end{array}$ & 4 & & & 2 & 2 \\
\hline $\begin{array}{l}3 \text { Asleep wakes up when } \\
\text { stimulated }\end{array}$ & 17 & & 1 & 7 & 9 \\
\hline 2 Drowsy & 37 & 1 & 4 & 8 & 24 \\
\hline 1 Quiet & 34 & 1 & 12 & 5 & 16 \\
\hline o No apparent effect & 5 & & 4 & & 1 \\
\hline-1 Anxious & 3 & 1 & 1 & 1 & \\
\hline-2 Anxious and agitatèd & 0 & & & & \\
\hline TOTAL: & 100 & 3 & 22 & 23 & 52 \\
\hline
\end{tabular}

weaned from the ventilator and the tracheal tubes were removed before 8:00 hours the next morning. In 17 more the tubes could be removed between 8:00 and 13:00 hours the same day. One patient who had mitral and aortic valve replacement was kept on mechanical ventilation for 72 hours postoperatively.

Patients ${ }^{1}$ views of the most unpleasant experience during the perioperative period

Twelve patients mentioned no unpleasant experience. Twenty-two patients said the mediastinal drains were their worst memory. This presented as pain during deep breathing, milking of the tubes or on their removal. Seventeen of the patients emphasized the tracheal tube. On further questioning, five patients found the tube "extremely uncomfortable". Five additional patients mentioned experiences related to the intubation. One mentioned the tracheo-bronchial toilet through the tube. Two complained of dysphonia for a few days after extubation. One patient complained of sore throat and one complained of thirst during the period of intubation.

Twenty patients mentioned pain either in the chest, or at the site of removal of a saphenous vein.

Four patients mentioned anxiety and one complained of nightmares in the postoperative period.

Table VI gives a detailed list of the patients' views of their worst memory. 
TABLE VI

Answers to the question:

"What is the worst thing to bear in such an experience? What is your worst memory?"

Nothing at all

Cases

The drains

The endotracheal tube

... or something related to intubation -tracheo-bronchial toilet:

-dysphonia:

-sore throat:

2

一thirst:

2

1

The pain

Anxiety

Nightmares

I.V. lines or punctures

Urinary catheter

Neck pain related to Swan Ganz

Changes of position

Constant disturbances for nursing procedures

Aerosol therapy

Face tent

Great asthenia

20

4

1

4

2

2

4

2

3

1

The tracheal tube

A summary of the patients' memory about intubation is presented in Table VII. Twenty-six patients volunteered information about the tube. Twenty-two of these said that they were comfortable or that it was relatively easy to tolerate. Four patients described major discomfort.

Forty-two of the 74 patients had no memory of the tube. Thirty-one remembered being relatively comfortable and one patient said that it was very difficult to tolerate his tube.

\section{Discussion}

Pulmonary 10.11 and myocardial ${ }^{11.12}$ dysfunction have been well documented after cardiac surgery. These dysfunctions last longer than the routine mechanical assistance whether the patients are weaned and have the trachea extubated a few hours after operation or early the next morning. The proponents of early tracheal extubation have demonstrated that early weaning and extubation can be accomplished safely in most cases despite these dysfunctions.

Time will tell whether an active approach to those patients who are alert and stable after cardiac surgery is associated with less morbidity than a conservative policy. Such an active approach includes early extubation and mobilization with an early and active program of physiotherapy, early removal of drains, catheters and intravenous lines, return of the patients to the ward as soon as they are stable. A parallel could be drawn between those patients and many who have abdominal operations. Ten or fifteen years ago, most patients spent one week to ten days in hospital after cholecystectomy, whereas today many are discharged three days postoperatively.

Successful weaning and tracheal extubation are contingent upon adequate ventilation. Adequate ventilation after morphine anaesthesia is related to the elimination of the drug. ${ }^{13.14}$ Early awakening through the use of short-acting agents and reversal of anaesthetics and relaxants are mandatory if one wishes systematically to promote early extubation.

Michel, et al. found that successful early weaning and tracheal extubation were achieved more often in patients who had shorter cardiopulmonary bypass time. Extubation could be achieved within ten hours of return to the I.C.U. in 18 of 22 patients whose bypass time was less

TABLE VII

Patients' Feelngs about the Tracheal Tuge

\begin{tabular}{ccccc}
\hline \hline & $\begin{array}{c}\text { No memory } \\
\text { of the tube }\end{array}$ & $\begin{array}{c}\text { Difficult } \\
\text { to tolerate } \\
\text { Great discomfort }\end{array}$ & $\begin{array}{c}\text { The tube was } \\
\text { relatively easy } \\
\text { to tolerate }\end{array}$ & Total \\
\hline $\begin{array}{c}\text { Information } \\
\text { voluntered }\end{array}$ & 42 & 4 & 22 & 26 \\
$\begin{array}{c}\text { Information } \\
\text { obtained by } \\
\text { questioning } \\
\text { Total: }\end{array}$ & 42 & 1 & 31 & 74 \\
\hline
\end{tabular}


than 100 minutes, while this was achieved in only nine of 22 patients who had bypass times longer than 100 minutes.

Alertness and comfort after operation are related to the residual effects of anaesthetic agents and to further analgesic sedative medication administered during the recovery period. The results of our study might have been different if the patients had received short acting anaesthetic agents instead of morphine.

The high incidence of amnesia (42 per cent) for the period of mechanical ventilation in our series confirms the usefulness of drugs such as diazepam ${ }^{15.16}$ which are commonly used in patients with tracheal tubes.

Fifty-two patients had no memory of the operating room. This is probably due to the combined effects of scopolamine, included in the premedication, and of diazepam administered at induction. Recent studies by Authier, et $a l^{17}$ indicate that the amnesia produced by diazepam can extend to the few minutes preceding its administration.

On the fifth postoperative day, only eight of our patients remembered being uncomfortable during mechanical ventilation and five of these related their discomfort to the tracheal tube which they found very hard to tolerate. Nevertheless, one out of every four patients spoke spontaneously about the tube. Most of the patients who volunteered information about the tube said it was relatively easy to tolerate. However, when asked about their most difficult experience, 22 patients mentioned the tube or something related to the intubation.

Our results contrast with those of Miller and Shada ${ }^{18}$ whose patients found the intubation a very trying experience. The majority of their subjects mentioned difficulties in breathing with the ventilator and a sensation of choking to death or of extreme panic. These authors do not mention the type of anaesthetics and of sedatives and analgesics administered during operation and in the immediate postoperative period. Their results may be partially related to such factors.

Two out of every three patients in our series retain the memory of an easier experience than had been expected or of a relatively easy one. The last third considered the experience difficult or more difficult than expected.

Miller and Shada have also reported ${ }^{18}$ mood changes after cardiac surgery. Following the period of euphoria commonly seen on the first postoperative day, there is frequently a change to a depressive mood on the third and fourth post- operative days. These changes seem to accompany fatigue and cardiac or pulmonary problems. If the general level of comfort could be increased safely by changing factors identified by the patients the depressive postoperative phase might be lessened and a greater proportion of our patients would have a relatively easier experience. Some of these factors are early tracheal extubation, use of small diameter sump-type drains which require no manipulations, early removal of drains and catheters, early discharge from the I.C.U. to the ward.

Besides the greater comfort of patients, the advocates of early tracheal extubation stress lower requirements for sedation, shorter stay in the I.C.U. and fewer respiratory complications.

\section{Lower Requirements for Sedation}

In a randomized study comparing patients after early extubation of the trachea with patients ventilated overnight, Quasha, et $a l .^{9}$ confirmed the lesser need for sedatives in the first group. Contrary to the belief that the need to reduce sedation in patients without a tracheal tube for fear of respiratory depression would be associated with a higher incidence of hypertensive episodes, these authors found no difference between the two groups with respect to haemodynamic variables, plasma norepinephrine or the percentage of patients requiring nitroprusside to treat hypertensive episodes.

\section{Shorter I.C.U. stay}

If criteria of cardiorespiratory stability only were used, most patients extubated after routine overnight ventilation could be discharged from the I.C.U. a few hours later. Assuming that patients extubated early after operation would spend the first night in the I.C.U. in any case, there is unlikely to be an important difference in the I.C.U. stay. This indeed was the case in the study by Quasha, et al.9

\section{Fewer respiratory complications}

The incidence of pulmonary complication is high after open-heart surgery, whether the trachea is extubated early ${ }^{19}$ or after overnight ventilatory support. ${ }^{20.21}$

In a recent sludy of pulmonary atelectasis and other respiratory complications after cardiopulmonary bypass, Gale, et al. ${ }^{10}$ found that the duration of postoperative mechanical ventilation was unrelated to the incidence of atelectasis. They also found a significant positive correlation between a short cardiopulmonary bypass time 
and plate atelectasis and between a large fluid load after bypass and segmental atelectasis. This confirms the findings of others ${ }^{19.22}$ and suggests that in many cases the process of atelectasis starts during the cardiopulmonary bypass.

A prospective study of two comparable groups would be useful to clarify the question. This should involve a group of patients whose tracheae are extubated after meeting criteria of weaning and a second group of patients who have been sedated and kept on a ventilator overnight after meeting the same criteria of cardiorespiratory stability and alertness.

\section{Conclusion}

Overnight tracheal intubation with respiratory assistance is easily tolerated by over 90 per cent of patients who have received morphine and diazepam during anaesthesia and during the period of ventilatory assistance. There is a high incidence of amnesia.

Some of the advantages claimed by proponents of early tracheal extubation appear inconclusive and we feel further study is desirable.

\section{SUMMARY}

Recent publications have advocated earlier weaning and early extubation of the trachea in patients after cardiac surgery. Greater comfort of the patients is one of the advantages claimed for this policy. One hundred consecutive adult patients were questioned on the fifth postoperative day to assess the relative comfort or discomfort of the patients during tracheal intubation and ventilation. Overnight tracheal intubation and ventilation were easily tolerated by over 90 per cent of patients who had received morphine and diazepan. There was a high incidence of amnesia. Some of the other claimed advantages appear inconclusive and further study is desirable to elucidate the effect of early removal of the tracheal tube upon the indicence of pulmonary complications.

\section{RÉSUMÉ}

Dans la plupart des centres de chirurgie cardiaque, les opérés sont gardés intubés et ventilés mécaniquement durant quelques heures après la chirurgie ou, de façon systématique, jusqu'au lendemain matin. Plusieurs publications récentes préconisent le sevrage du respirateur et l'extubation précoce des patients. D'après ceux qui re- commandent cette attitude, les malades seraient ainsi plus confortables, auraient besoin de moins de sédation, pourraient être mobilisés plus rapidement, présenteraient moins de complications pulmonaires, et passeraient moins de temps dans les unités de soins intensifs.

A vant de reconsidérer la ligne de conduite conservattice (assistance respiratoire jusquau lendemain matin) adoptée dans notre institution. nous avons voulu évaluer le confort ou l'inconfort relatif lié à l'intubation et à la ventilation mécanique.

A cette fin, nous avons questionné cent opérés consécutifs, le cinquième ou le sixième jour après chirurgie cardiaque. Tous nos patients avaient été avertis qu'ils s'éveilleraient après l'intervention avec un tube endotrachéal et avaient été rassurés à ce sujet. Ils ont tous reçu, à doses variables, du diazepam et de la morphine en cours d'anesthésie et durant la phase de ventilation mécanique postopératoire. Des questions d'ordre général, en rapport avec l'expérience qu ils venaient de vivre, ont été posées au début de l'interview, alors que celles se rapportant au tube trachéal ont été gardées pour la fin de l'entrevue, ceci afin de fournir aux patients l'occasion d'aborder spontanément le sujet du tube trachéal.

Vingt-six patients nous ont parlé spontanément du tube; 22 pour nous dire qu'il était relativement facile à tolérer et quatre pour nous dire qu'ils en gardaient une très mauvaise impression. En questionnant les 74 autres, nous avons appris que 42 opérés ne se souvenaient de rien de toute la période d'intubation, qu'un seul malade en gardait un souvenir pénible et que 31 autres patients avaient trouvé l'expérience relativement façile. D'après les notes au dossier, 40 malades sont apparus inconfortables, souffrants ou anxieux à l'infirmière à un moment ou l'autre de la période de ventilation mécanique. Lors de l'entrevue, seulement cinq de ces $\mathbf{4 0}$ patients se souvenaient avoir été inconfortables durant cette même période (le tube était mis en cause dans quatre cas), 19 patients ne se rappelaient de rien et les 16 autres estimaient avoir été confortables.

Interrogés sur le souvenir le plus désagréable de cette période, 12 patients n'ont rien eu à répondre. Pour 22 d'entre eux, les drains thoraciques constituent le pire souvenir, pour 22

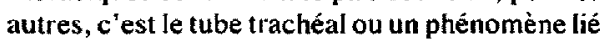
à l'intubation (dysphonie, dysphagie, succion endotrachéale) et chez 20 autres malades, c'est la douleur au niveau des plaies.

Les avantages mis de l'avant par ceux qui 
préconisent l'extubation précoce sont discutés. La poursuite des études sur le sujet apparaît désirable, en particulier en ce qui concerne l'incidence des complications pulmonaires.

\section{REFERENCES}

1. Tarhan, S. \& Moffitt, E.A. Anesthesia and supportive care during and after cardiac surgery. Ann. Thorac. Surg. 1 I: 64-89(1971).

2. Midell, A.l., Skinner, D.B., DeBoer, A., \& Bermudez, G. A review of pulmonary problems following valve replacement in 100 consecutive patients. Ann. Thorac. Surg. 18: 219-227 (1974).

3. Estafanous, F.G. Respiratory care following open-heart surgery. Surg. Clin. N. Am. 55: 1229-124I (1975).

4. LowENSTEIN, E. \& Bl.AND, J.H.L. Anesthesia for cardiac surgery. In: Cardiac Surgery. Edited by Norman, J.C. New York: Appleton-CenturyCrofts, pp. 75-102 (1972).

5. CAMPBELL, G.S. Respiratory failure in surgical patients. Current Problems in Surgery XIII, 2; 57-60 (1976).

6. Prakash, O., Jonson, B., Meju, S., Bos, E., Hugenholtz, P.G., Nauta, J., \& Hekman, W. Criteria for early extubation after intracardiac surgery in adults. Anesth. Analg. 56: 703-708 (1977).

7. Klineberg, P.L., Geer, R.T., Hirsh, R.A., \& AUKBURG, S.J. Early extubation after coronary artery bypass graft surgery. Crit. Care Med. 5: 272-274 (1977).

8. Michel, L., McMichan, J.C., Marsh, H.M., \& RE,HDER, K, Early extubation after cardiac surgery: appraisal of the physiological criteria. Abstracts of Scientific Papers, A.S.A: Annual Meeting, Chicago, Illinois, pp. 209-210 (1978).

9. Quasha, A.L., Loeber, N.V., Feeley, T.W. RoIzen, M., \& UlLyot, D.J. Early versus late extubation of patients following coronary artery bypass graft surgery. Abstracts of Scientific Papers, A.S.A. Annual Meeting, Chicago, lllinois, pp. 211-212 (1978).

10. Gale, G.D. Sanders, D.E. The BartlellEdwards incentive spirometer: a preliminary assessment of its use in the prevention of atelectasis after cardiopulmonary bypass. Canad. Anaesth. Soc. J. 24: 408-416 (1977).

11. Kouchoukos, N.T. \& KarP, R.B. Functional disturbances following extracorporeal circulatory support in cardiac surgery, In: Current Techniques in Extracorporeal Circulation. Edited by Ionescu, M.I. \& Wooler, G.H. London: Butterworths, pp. 245-296 (1976).

12. Brrick, R.J., Young, P., \& Teasdale, S. Systolic time interval changes after aortocoronary bypass. Canad. Anaesth. Soc. J. 24: 175-185 (1977).

13. Stanley, T.H. \& Lathrop, G.D. Urinary morphine excretion during and after morphine anaesthesia for open-heart surgery in children. Canad. Anaesth. Soc. J. 23: 640-647 (1976).

14. YЕH, S.Y. Urinary excretion of morphine and its metabolites in morphine-dependent subjects. J. Pharmacol. Exp. Ther. 192: 201-210 (1975).

IS. Claake, P.R.F., Eccersley, P.S., Frisby, J.P., \& ThORnton, J.A. The amnesic effect of diazepam (Valium). Brit. J. Anaesth. 42: 690-697 (1970).

16. Ghoneim, M.M. \& Mewaldt, S.P. Studies on human memory: the interactions of diazepam, scopolamine, and physostigmine. Psychopharmacology 52: 1-6(1977).

17. Authier, L., Chapados, R., Sindon, A., \& Gagnon, M.A. Amnésie et autres effets du diazepam dans la prémédication el l'induction de l'anesthésie. Canad. Anaesth. Soc. J. 25: 297-302 (1978).

18. Miller, P. \& Shada, E.A. Preoperative information and recovery of open-heart surgery patients. Heart \& Lung 7: 486-493 (1978).

19. Turnbull, K.W. Miyagishima, R.T., \& GeREIN, A.N. Pulmonary complications and cardiopulmonary bypass: a clinical study in adults. Canad. Anaesth. Soc. J, 21: 181-194 (1974).

20. SLAADEN, R.N.\& JENKINS, L.C. Intermittent mandatory ventilation and controlled mechanical ventilation without positive end-expiratory pressure following cardiopulmonary bypass. Canad. Anaesth. Soc. J. 25: 166-172 (1978).

21. Gale, G.D., Teasdale, S.J., Sanders, D.E., Bradwell, J., Russell, A., Solaric, B., \& YORK, J.E. Pulmonary atelectasis and other respiratory complications after cardiopulmonary bypass. An investigation of aetiological factors. Canad. Anaesth. Soc. J. 26: 15-21 (1979).

22. Hewson, J.R. Perfusion characteristics during cardiopulmonary bypass and subsequent changes in alveolar-arterial oxygen tension gradients. Anesth. Analg. 57: 298-302 (1978). 